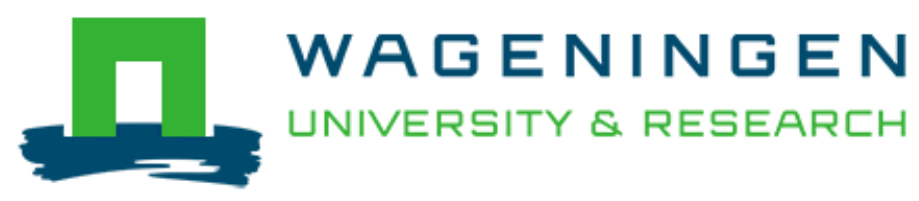

\title{
Small food texture modifications can be used to change oral processing behaviour and to control ad libitum food intake
}

Mosca, A. C., Pohlenz Torres, A., Slob, E., de Graaf, K., McEwan, J. A., \& Stieger, M.

This is a "Post-Print" accepted manuscript, which has been Published in "Appetite"

This version is distributed under a non-commercial no derivatives Creative Commons (a) $(1) \Theta$ reproduction in any medium, provided the original work is properly cited and not used for commercial purposes. Further, the restriction applies that if you remix, transform, or build upon the material, you may not distribute the modified material.

Please cite this publication as follows:

Mosca, A. C., Pohlenz Torres, A., Slob, E., de Graaf, K., McEwan, J. A., \& Stieger, M. (2019). Small food texture modifications can be used to change oral processing behaviour and to control ad libitum food intake. Appetite, 142, [104375].

https://doi.org/10.1016/j.appet.2019.104375

You can download the published version at:

https://doi.org/10.1016/j.appet.2019.104375 

change oral processing behaviour and to control ad libitum food intake

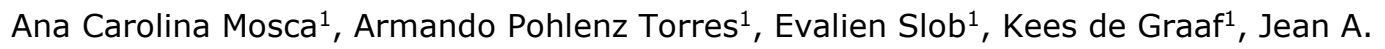
McEwan², Markus Stieger ${ }^{1}$

${ }^{1}$ Wageningen University and Research, Division of Human Nutrition and Health, P.O. Box 17, 96700 AA Wageningen, The Netherlands

10 2Jean A McEwan Consulting, UK

17 Corresponding author

18 Tel: +31317481694

19 Email: markus.stieger@wur.nl 
Little is known whether small modifications of food texture are sufficient to influence satiation. This study used four iso-caloric yogurts differing in viscosity (low/high) and granola particle size (small/large) to investigate the influence of small texture modifications on oral processing behaviour, eating rate and ad libitum intake. Yogurt viscosity differed by a factor of $1.57 \mathrm{x}$ to 1.81x. Granola particle size was $6 \mathrm{~mm}$ and $12 \mathrm{~mm}$ (2-fold difference). Granola particle concentration based on weight was constant $(15 \% \mathrm{w} / \mathrm{w})$. Oral processing behaviour was quantified by video recording consumers eating yogurt ad libitum $(n=104)$. Ratings for appetite, liking and product familiarity were also quantified.

A decrease in yogurt viscosity significantly decreased spoon size, number of chews per spoon and oral exposure time per spoon but did not significantly affect eating rate and ad libitum intake. A decrease in granola particle size from $12 \mathrm{~mm}$ to $6 \mathrm{~mm}$ at constant weight concentration significantly increased number of chews per spoon and decreased spoon size, eating rate and ad libitum intake without affecting liking. The differences in eating rate and ad libitum intake between yogurts containing small and large granola particles were $5 \mathrm{~g} / \mathrm{min}(7 \%)$ and $17 \mathrm{~g}(5 \%)$, respectively. We suggest that the volume of granola particles added to the yogurt and not the size of particles per se was the driver of oral processing behaviour.

We conclude that relatively small modifications in yogurt texture, especially granola particle size, are sufficient to change oral processing behaviour and ad libitum intake. These findings demonstrate that small texture modifications of foods, such as the size of granola particles added to yogurt, can be used to modulate eating rate and food intake within a meal. 


\section{INTRODUCTION}

47 Increasing concerns regarding overweight and obesity require a better understanding of factors contributing to food intake. Therefore, it is of great interest to quantify the extent to which the modulation of food properties such as texture can be used to regulate the amount of food consumed within a meal.

To define relationships between food properties and intake, it is necessary to take into consideration the oral processing of foods. The food products available on the market require different oral processing efforts to transform the initial food structure into a bolus that can be safely swallowed. Hard, chewy, crunchy and less moist/lubricated foods need more chewing and are kept longer in the oral cavity in comparison to liquids or soft foods (Forde et al., 2013; Forde et al., 2017; Wee et al., 2018; Aguayo-Mendoza et al., 2019). For instance, $50 \mathrm{~g}$ of mashed potatoes required about 27 chews and were kept for $29 \mathrm{~s}$ in mouth before swallowing, while the same amount of tortilla chips required 488 chews and was kept for $349 \mathrm{~s}$ in mouth (Forde et al., 2013). These differences in oral processing behaviour have a profound impact on food and energy intake. Among 35 food products that represent a wide range of textures, Forde et al. (2013) observed that consumption in smaller bites, with higher number of chews and longer oral residence duration imparted higher expected satiation. The lowest (canned tomato) and the highest (hotdog) expected satiation scores differed by approximately 3 -fold. Similarly, in a study that compared 20 different pre-packed meals, Ferriday et al. (2016) observed that slower eating rates, longer intervals between bites and longer oral exposure time resulted in higher expected satiation, greater post-meal fullness (ratings obtained immediately after eating a fixed portion) and greater satiety (calculated as the total area under the curve of fullness ratings over time), suggesting that eating rate affects the amount and energy of foods consumed within and between meals.

Changes in the satiating capacity of foods through modulations of textural properties have been extensively reported (de Wijk et al., 2008; Zijlstra et al., 2009; Bolhuis et al., 2014; Robinson et al., 2014; Lasschuijt et al., 2017; McCrickerd et al., 2017). Zijlstra et al. (2008) compared the ad libitum intake of three milk-based products varying in viscosity. The products were consumed with a thick straw. A 9-fold increase in viscosity (comparing liquid with semi-solid foods) led to a $30 \%(243 \mathrm{~g}$ ) reduction in intake, whereas a 3 -fold increase in viscosity (comparing liquid with semi-liquid foods) reduced intake by $14 \%$ (110g) (Zijlstra et al., 2008). This shows that the larger the texture differences, the larger the impact on food and energy intake within a meal. Similarly, Lasschuijt et al. (2017) observed differences in ad libitum intake of semi-solid gels differing in fracture properties. Hard gels were chewed approximately 2.5 times more per bite, yielding a $42 \%$ reduction in eating rate and a $21 \%(\sim 40 \mathrm{~g})$ reduction in intake. In these studies a prolonged oral exposure resulting from lower eating rates was suggested as the reason for decreases in food intake (Zijlstra et al., 2008; de Graaf, 2012; Lasschuijt et al., 2017).

83 More subtle modifications of food texture have also been shown to affect food intake. Bolhuis et 84 al. (2014) compared the oral processing behaviour and ad libitum intake of soft and hard 85 versions of hamburgers and rice salads. Hamburgers varied in type of bread (soft and hard) and 86 rice salads in type of rice (risotto and white rice). The consumption of hard foods was 
characterized by smaller bites, longer oral exposure time and higher numbers of chews, resulting in a $32 \%$ reduction in eating rate and $16 \%(63 \mathrm{~g})$ reduction in ad libitum intake in comparison to the soft versions of the same foods (Bolhuis et al., 2014). Tarrega, Marcano \& Fiszman (2016) reported that the expected satiation of yogurts with added fruit particles increased by $28 \%$ when yogurt viscosity was increased by 2.6 -fold. The addition of lyophilized pineapple cubes to yogurts contributed to an increase in expected satiation of low viscosity yogurt by $23 \%$ and of high viscosity yogurt by $6 \%$. Eating rate and food intake were not quantified in this study. The authors attributed this increase in expected satiating capacity to the more complex oral processing behaviour that a high viscosity yogurt matrix and chewable fruit particles require. McCrickerd et al. (2017) modulated the eating rate and oral processing behaviour of rice porridges by changing the proportions of ground rice grains and liquid stock. The thick porridge (containing whole brown rice and semi-ground white rice grains; $1: 1$ rice:stock) was consumed slower, with larger bite sizes, longer oral exposure time per bite and more chews per bite than the thin porridge (containing rice grains fully ground to powder; 5:1 rice:stock). A 41\% decrease in eating rate of thick porridge resulted in an approximate $12 \%(63 \mathrm{~g})$ decrease in intake in comparison to thin porridge (McCrickerd et al., 2017). Changes in the textural properties of foods have been shown to impact satiety responses. Zhu et al. (2013) modified the viscosity of semi solids meals by adding guar gum. Eating rate of the high viscosity meal was $31 \%$ slower than that of the low viscosity meal. Although ad libitum intake did not vary between the two meals, the high viscosity meal yielded an appetite suppression, with a reduction in postprandial hunger and desire to eat, increased fullness, slower gastric emptying rate and a lower postprandial plasma concentration of the hormone glucose-dependent insulinotropic peptide. The glycemic response was also affected by differences in viscosity, with the postprandial glucose plasma concentration being higher after the consumption of the high viscosity meal (Zhu et al. 2013).

Even though large reductions in food and energy intake within a meal can be achieved when the textural properties of foods are modified considerably, large texture modifications have a lower potential of being accepted and sustained overtime, as consumers should be willing to consume a very different product. For that reason, further investigations are required to better understand the extent to which small and subtle modifications of food texture can regulate food intake within a meal. In this context, this study aims to determine the influence of small variations in yogurt viscosity and granola particle size on oral processing behaviour, eating rate and ad libitum intake. We hypothesize that small modifications in viscosity and particle size are sufficient to change oral processing behaviour and to control the amount of food consumed within a meal.

\section{MATERIALS \& METHODS}

Medical ethical approval for this study was obtained from the medical ethical committee of Wageningen University (NL62080.081.17). 


\subsection{Subjects}

A total of $n=104$ participants (76 females, 28 males, average age: $21 \pm 3 y$, range: 18-36; average BMI: $21 \pm 2 \mathrm{~kg} / \mathrm{m}^{2}$, range: $18-26$ ) completed the study. Recruitment was done via the database of the Division of Human Nutrition of Wageningen University, social media and printed advertisements posted at the University Campus boards. Participants had to fulfil the following criteria: Dutch nationality of European ancestry, born in The Netherlands, age between 18-45 years, regular consumer of yogurt (defined as consume yogurt products at least once a week), good general and oral health (self-reported), normal smell and taste functions (self-reported), normal body mass index (BMI $18.5-25 \mathrm{~kg} / \mathrm{m}^{2}$ ) (based on self-reported weight and height) and no dental braces or piercings in/or around the mouth (except removable piercings). Participants with food allergies or intolerances for gluten, dairy or nuts, mastication and/or swallowing problems, history of eating disorders and those that followed an energy restricted diet during the prior 2 months as well as pregnant and lactating women were not included. All participants gave written informed consent prior to the first session.

\subsection{Test products}

In total six yogurts with granola were prepared. Yogurts varied in viscosity and size of granola particles. A $2 \times 3$ full factorial design was used with 2 yogurt viscosities (low/high) and 3 granola particle sizes (powder/small/large). Granola was added to yogurts at $15 \% \mathrm{w} / \mathrm{w}$. All six samples had the same ingredient composition and calorie content. The granola powder displayed a very different behaviour upon mixing with yogurt in comparison to the small and large granola particles. It took up water from the yogurt matrix shortly after mixing, leading to the swelling of the powdered particles and to an increase in viscosity and stickiness of the yogurt accompanied by a decrease in palatability. Because the aimed experimental conditions with respect to yogurt viscosity and palatability were not met for the two yogurts with added granola powder, the data referent to these two samples was removed from the data analysis of this study. The data of four samples which met the target experimental conditions (low/high yogurt viscosity with small/large granola particles) is reported. We acknowledge that the presence of the two yogurts with powdered granola particles in the data collection (all participants consumed all six samples) might have influenced the results of the current study. As outlined in section 2.3, participants attended two sessions per week, with at least 1 day between sessions. We suggest that potential carry over effects in this case are very limited.

\subsubsection{Yogurts}

As high viscosity yogurt, the commercially available Optimel Greek style yogurt - natural (FrieslandCampina, NL) was used. This yogurt contains $54 \mathrm{kcal}, 3.5 \mathrm{~g}$ carbohydrate and $9 \mathrm{~g}$ protein per $100 \mathrm{ml}$. To obtain the low viscosity yogurt, the commercially available Optimel Greek style yogurt was stirred in a mixer (model N50, Hobart Corporation, United States) with a "B Flat" beater for 40 min at medium speed (option " 2 " of N50 mixer) followed by stirring for 30 min at low speed (option " 1 " of N50 mixer). 
Flow curves of the yogurts were determined using an Anton Paar MCR 300 rheometer (Anton Paar $\mathrm{GmbH}$, Austria) operating with a 4 wings stirrer of $22 \mathrm{~mm}$ diameter (ST 22-4/Q1, Anton Paar $\mathrm{GmbH}$, Austria) at a shear rate range of 0.1 to $100 \mathrm{~s}^{-1}$. Yogurts were removed from the refrigerator and led to equilibrate to room temperature. Measurements were performed in triplicate at $25^{\circ} \mathrm{C}$.

At shear rates of $0.1,1,10$ and $100 \mathrm{~s}^{-1}$, the viscosities of the thick yogurt were $73 \pm 9,69 \pm 8$, $9 \pm 1$ and $1.1 \pm 0.1 \mathrm{~Pa} . \mathrm{S}$, while the viscosities of the thin yogurt at the respective shear rates were $42 \pm 3,38 \pm 6,5 \pm 1$ and $0.7 \pm 0.1$ Pa.s. The viscosity differences between low and high viscosity yogurts ranged from $1.57 x$ to $1.81 \mathrm{x}$. For the sake of simplicity, we refer to these differences in viscosity as a factor of $1.7 x$. A preliminary sensory test (focus group discussion, data not shown) confirmed that the difference in viscosity between the yogurts was perceivable as a difference in thickness. We did not evaluate whether the differences in granola particle size affected the perception of granola related texture attributes such as crunchiness and grittiness by a similar magnitude as differences in viscosity affected thickness perception.

\subsubsection{Granola particles}

Commercially available granola (BioFamilia, Switzerland) was used. Granola was composed of oat flakes, sugar, cereal crispies (maize, rice, sugar, whole grain flour - wheat, rye, barley, barley malt, cocoa powder and table salt), sunflower oil, flour (wheat, rye), coconut flakes, wheat germ, dextrose, roasted hazelnuts, honey and table salt (460 kcal, $18 \mathrm{~g}$ fat, $64 \mathrm{~g}$ carbohydrate and $9 \mathrm{~g}$ protein per $100 \mathrm{~g}$ ). Granola was sieved using stainless steel sieves varying in mesh size (2, 5.6 and $12.5 \mathrm{~mm}$, Retsch, Germany) to obtain three fractions: powder ( $<2$ $\mathrm{mm})$, small $(\sim 6 \mathrm{~mm})$ and large $(\sim 12 \mathrm{~mm})$ particles.

\subsection{Experimental procedure}

Participants attended a total of six sessions of approximately 30 min over a period of 3 weeks. To minimize fatigue and potential carry over effects, participants attended no more than 2 sessions per week with at least 1 day between consecutive sessions. The test sessions took place at breakfast time between 7:30 - 09:30 h. For each participant, six sessions with the same starting time were scheduled according to his/her usual breakfast time. The sessions were carried out in sensory booths at $20^{\circ} \mathrm{C}$ under normal light conditions. Participants were instructed to come in a fasted state by refraining from eating or drinking, except for water, after 22:00 $\mathrm{h}$ the day before the test session.

\subsubsection{Oral processing behaviour}

A digital camera (Logitech webcam, resolution $640 \times 280$ pixels) was positioned in front of the subject, close enough to take a complete picture of the face without causing distraction or discomfort. Participants were instructed to consume the yogurt naturally while looking straight 


\section{4}

225 into the webcam. They could not see themselves in the computer screen. Video recordings were done using the Kinovea software version 0.8.24 (Kinovea, France).

Videos were decoded using the Observer software version XT 11 (Noldus Information Technology, the Netherlands). A coding scheme was developed to record the frequency counts of spoons, chews and swallows during a complete eating event as previous described (Bolhuis et a., 2013; Forde et al., 2013; Ferriday et al., 2016). Since from the video analysis we cannot distinguish chews from tongue movements, all vertical displacements of the jaw were defined and counted as a chew. Measures of total eating duration (s), total oral exposure time (period of food in the mouth) (s), inter-spoon interval (period of no food in the mouth) (s) were directly extracted from the videos. These parameters together with the measures of amount of yogurt consumed were used to derive the parameters oral exposure time/spoon, eating rate $(\mathrm{g} / \mathrm{min})$, spoon size $(\mathrm{g})$, chews/spoon and rate of spooning and chewing $\left(\mathrm{m}^{-1}\right)$. A description of the oral processing parameters considered in this study is listed in Table 1. Coding of all video recordings was done by a single coder. To develop the coding scheme, three researchers watched several videos together and agreed on the coding scheme. Coding was not crosschecked by a second coder which has previously been recommended to increase reliability of video decoding (Hennequin et al., 2005).

Table 1. Oral processing parameters extracted from video recordings.

\begin{tabular}{|c|c|}
\hline Parameter & Definition \\
\hline Eating duration (s) & $\begin{array}{l}\text { The total duration of the eating event. Comprises the time from the first spoon } \\
\text { to the final swallow }\end{array}$ \\
\hline $\begin{array}{l}\text { Total oral exposure } \\
\text { time (s) }\end{array}$ & Period that food remains in the mouth during the eating event \\
\hline $\begin{array}{l}\text { Oral exposure time } \\
\text { per spoon }(s)\end{array}$ & Average period that food remains in the mouth during each spoonful \\
\hline $\begin{array}{l}\text { Total interval between } \\
\text { spoons (s) }\end{array}$ & $\begin{array}{l}\text { Period that there was no food in the mouth during the eating event. Comprises } \\
\text { the time between a final swallow and a subsequent spoonful }\end{array}$ \\
\hline Eating rate $(\mathrm{g} / \mathrm{min})$ & The amount of food $(\mathrm{g})$ consumed over the total oral exposure time \\
\hline $\begin{array}{l}\text { Total number of } \\
\text { spoons }(n)\end{array}$ & The total number of spoons taken during the eating event \\
\hline $\begin{array}{l}\text { Total number of } \\
\text { chews }(n)\end{array}$ & The total number of chewing cycles during the eating event \\
\hline $\begin{array}{l}\text { Total number of } \\
\text { swallows }(n)\end{array}$ & $\begin{array}{l}\text { The total number of swallows during the eating event. Includes intermediate } \\
\text { swallows between chewing cycles and final swallows }\end{array}$ \\
\hline Chews per spoon & The average number of chewing cycles per spoonful \\
\hline Spoon size $(\mathrm{g})$ & The average amount of food $(\mathrm{g})$ consumed per spoonful \\
\hline Spooning rate $\left(\mathrm{min}^{-1}\right)$ & The total number of spoons over the total eating duration \\
\hline Chewing rate $\left(\min ^{-1}\right)$ & The total number of chewing cycles over the total oral exposure time \\
\hline
\end{tabular}

\subsubsection{Ad libitum food intake}

An amount of $1 \mathrm{Kg}$ of yogurt ( $850 \mathrm{~g}$ yogurt with $150 \mathrm{~g}$ granola) was served to participants in 2 $L$ ceramic bowls coded with three-digit random codes. The total energy content per serving was 
$1149 \mathrm{kcal}$. The presentation order of the yogurts was balanced over participants and sessions using a modified Latin square design. A glass with still mineral water ( $\sim 140 \mathrm{~g}$ ) previously weighed was also provided. Yogurt was weighed the day before and kept refrigerated at $5{ }^{\circ} \mathrm{C}$. Granola particles were also weighed the day before and were added to the yogurt immediately before the start of consumption. Participants were instructed to eat freely until feeling pleasantly full. A metallic tablespoon was used for yogurt consumption. The size of the tablespoon is common for consumption of yogurts and soups in the Netherlands. Participants were not informed that food intake was the primary parameter of interest. The amount eaten, used as indication of satiation, was calculated as the difference between the initial and final weights of the bowl.

\subsubsection{Appetite, liking and familiarity ratings}

Hunger, fullness and desire to eat were assessed before and after the ad libitum consumption using a $100 \mathrm{~mm}$ VAS anchored "not at all" and "very much". Liking was assessed after the first spoon by all subjects $(n=104)$. After the data collection of the first 52 subjects, a preliminary data analysis indicated that information on familiarity and desire to eat the product again and liking at the end of consumption would allow to better understand the palatability of the yogurts. Therefore, the last 52 subjects rated familiarity, after the first spoon and liking and desire to eat the product again after the last spoon in addition to liking after the first spoon. Ratings were obtained using a $100 \mathrm{~mm}$ VAS anchored "not at all" and "very much". All measurements were done using Qualtrics ${ }^{\circledR}$ research CORE ${ }^{T M}$, United States.

\subsection{Data analysis}

Statistical analyses were performed using XLSTAT (Addinsoft, France). Three-way ANOVA was used to check for effects of subjects, yogurt and granola on intake, appetite, liking, familiarity and oral processing parameters. Interactions between yogurt and granola were included in the analysis/model. Tukey HSD was used as a post-hoc test for differences between mean values. All tests were carried out at a significance level of $a=0.05$. Pearson's correlation coefficients $(r)$ were calculated to explore how intake was affected by eating rate or other oral processing parameters.

\section{RESULTS}

\subsection{Appetite ratings}

The differences in hunger, fullness and desire to eat rated before and after consumption were similar (no significant differences) for the four yogurts with added granola particles (Table 2). This shows that subjects ate until feeling pleasantly full independent of type of yogurt. 
266 Table 2. Summary of appetite ratings, hedonic ratings, oral processing parameters and intake (mean (SEM)) of yogurts differing in viscosity (low/high) with added granola particles differing

268 in size (small/large) $(n=104)$.

\begin{tabular}{|c|c|c|c|c|c|c|c|c|c|}
\hline & & & & & & & & & \\
\hline & & $\begin{array}{c}\text { Low } \\
\text { viscosity/ } \\
\text { Small } \\
\text { particles }\end{array}$ & $\begin{array}{l}\text { Low } \\
\text { viscosity/ } \\
\text { Large } \\
\text { particles }\end{array}$ & $\begin{array}{c}\text { High } \\
\text { viscosity/ } \\
\text { Small } \\
\text { particles }\end{array}$ & $\begin{array}{c}\text { High } \\
\text { viscosity/ } \\
\text { Large } \\
\text { particles }\end{array}$ & $\begin{array}{l}\text { Average } \\
\text { low } \\
\text { viscosity }\end{array}$ & $\begin{array}{c}\text { Average } \\
\text { high } \\
\text { viscosity }\end{array}$ & $\begin{array}{l}\text { Average } \\
\text { small } \\
\text { particles }\end{array}$ & $\begin{array}{l}\text { Average } \\
\text { large } \\
\text { particles }\end{array}$ \\
\hline \multirow{3}{*}{$\begin{array}{c}\text { Change in } \\
\text { appetite } \\
\text { (after-before } \\
\text { consumption) }\end{array}$} & Hunger & $-53(2)^{a}$ & $-50(2)^{a}$ & $-52(2)^{a}$ & $-51(2)^{a}$ & $-51(2)^{a}$ & $-52(2)^{a}$ & $-52(2)^{a}$ & $-50(2)^{a}$ \\
\hline & Fullness & $53(3)^{a}$ & $52(2)^{a}$ & $52(3)^{a}$ & $52(3)^{a}$ & $53(2)^{a}$ & $52(2)^{a}$ & $53(2)^{a}$ & $52(2)^{a}$ \\
\hline & Desire to eat & $-56(2)^{a}$ & $-53(2)^{a}$ & $-53(2)^{a}$ & $-52(3)^{a}$ & $-55(2)^{a}$ & $-53(2)^{a}$ & $-54(2)^{a}$ & $-53(2)^{a}$ \\
\hline \multirow{5}{*}{$\begin{array}{l}\text { Hedonic } \\
\text { ratings }\end{array}$} & \multirow{5}{*}{$\begin{array}{l}\text { Liking (after } \\
\text { first spoon) } \\
\text { Liking (after last } \\
\text { spoon) } \\
\text { Difference in } \\
\text { liking } \\
\text { Familiarity } \\
\text { Desire to eat } \\
\text { product again }\end{array}$} & $65(2)^{b}$ & $64(2)^{b}$ & $69(1)^{a}$ & $67(2)^{a b}$ & $64(1)^{b}$ & $68(1)^{a}$ & $67(1)^{a}$ & $65(1)^{a}$ \\
\hline & & $70(2)^{a}$ & $72(2)^{a}$ & $75(2)^{a}$ & $73(2)^{\mathrm{a}}$ & $71(2)^{a}$ & $74(1)^{a}$ & $72(1)^{a}$ & $72(1)^{a}$ \\
\hline & & $3(2)^{a}$ & $7(2)^{a}$ & $4(1)^{a}$ & $4(1)^{a}$ & $5(1)^{a}$ & $4(1)^{a}$ & $3(1)^{a}$ & $5(1)^{a}$ \\
\hline & & $55(4)^{b}$ & $58(3)^{b}$ & $69(3)^{a}$ & $72(3)^{a}$ & $56(3)^{b}$ & $71(2)^{\mathrm{a}}$ & $62(3)^{a}$ & $65(2)^{a}$ \\
\hline & & $64(3)^{b}$ & $65(3)^{b}$ & $74(2)^{a}$ & $71(2)^{a b}$ & $65(2)^{b}$ & $72(2)^{a}$ & $69(2)^{a}$ & $68(2)^{a}$ \\
\hline \multirow{12}{*}{$\begin{array}{l}\text { Oral } \\
\text { processing } \\
\text { behaviour }\end{array}$} & Total spoons (n) & $27(1)^{a}$ & $26(1)^{a}$ & $25(1)^{b}$ & $25(1)^{b}$ & $27(1)^{a}$ & $25(1)^{b}$ & $26(1)^{a}$ & $26(1)^{a}$ \\
\hline & Total chews (n) & $458(17)^{a}$ & $424(15)^{b}$ & $443(15)^{a b}$ & $437(17)^{a b}$ & $441(11)^{a}$ & $440(11)^{a}$ & $451(11)^{a}$ & $430(11)^{b}$ \\
\hline & $\begin{array}{c}\text { Total swallows } \\
\text { (n) }\end{array}$ & $47(2)^{\mathrm{ab}}$ & $48(2)^{a}$ & $43(2)^{c}$ & $44(2)^{\mathrm{bc}}$ & $47(1)^{a}$ & $44(1)^{b}$ & $45(1)^{a}$ & $46(1)^{a}$ \\
\hline & $\begin{array}{l}\text { Eating duration } \\
\text { (s) }\end{array}$ & $406(13)^{a}$ & $390(12)^{a}$ & $403(12)^{a}$ & $406(14)^{a}$ & $398(9)^{a}$ & $405(9)^{a}$ & $405(9)^{a}$ & $398(9)^{a}$ \\
\hline & $\begin{array}{l}\text { Total oral } \\
\text { exposure time } \\
\text { (s) }\end{array}$ & $347(11)^{a}$ & $329(10)^{a}$ & $344(10)^{a}$ & $344(13)^{a}$ & $338(7)^{a}$ & $344(8)^{a}$ & $345(8)^{a}$ & $337(8)^{a}$ \\
\hline & $\begin{array}{l}\text { Total interval } \\
\text { between spoons } \\
\text { (s) }\end{array}$ & $59(3)^{a}$ & $61(3)^{a}$ & $60(3)^{a}$ & $62(3)^{a}$ & $60(2)^{a}$ & $61(1)^{a}$ & $59(2)^{a}$ & $62(2)^{a}$ \\
\hline & $\begin{array}{c}\text { Eating rate } \\
(\mathrm{g} / \mathrm{min})\end{array}$ & $60(2)^{b}$ & $65(2)^{a}$ & $60(2)^{b}$ & $64(2)^{a}$ & $63(1)^{a}$ & $62(1)^{a}$ & $60(1)^{b}$ & $65(1)^{a}$ \\
\hline & $\begin{array}{l}\text { Spooning rate } \\
\text { (spoon/min) }\end{array}$ & $4.0(0.1)^{a}$ & $4.1(0.1)^{a}$ & $3.7(0.1)^{b}$ & $3.7(0.1)^{b}$ & $4.1(0.1)^{a}$ & $3.7(0.1)^{b}$ & $3.9(0.1)^{a}$ & $3.9(0.1)^{a}$ \\
\hline & $\begin{array}{l}\text { Chewing rate } \\
\text { (chews/min) }\end{array}$ & $79(1)^{a}$ & $78(2)^{a}$ & $78(1)^{a}$ & $77(1)^{a}$ & $78(1)^{a}$ & $77(1)^{a}$ & $78(1)^{a}$ & $77(1)^{a}$ \\
\hline & $\begin{array}{l}\text { Spoon size } \\
\text { (g/sip) }\end{array}$ & $13.5(0.5)^{b}$ & $14(1)^{a}$ & $15(1)^{a}$ & $15(1)^{a}$ & $14.0(0.4)^{b}$ & $14.9(0.4)^{a}$ & $14.0(0.4)^{b}$ & $14.8(0.4)^{a}$ \\
\hline & $\begin{array}{c}\text { Chews/spoon } \\
(n)\end{array}$ & $18(1)^{b}$ & $17(1)^{c}$ & $20(1)^{a}$ & $19(1)^{a b}$ & $17.7(0.4)^{b}$ & $19.2(0.5)^{a}$ & $18.9(0.5)^{a}$ & $18.0(0.4)^{b}$ \\
\hline & $\begin{array}{c}\text { Oral exposure } \\
\text { time/spoon (s) }\end{array}$ & $13.9(0.4)^{b}$ & $13.5(0.4)^{b}$ & $15.1(0.5)^{\mathrm{a}}$ & $14.8(0.5)^{a}$ & $13.7(0.3)^{\mathrm{b}}$ & $14.9(0.3)^{a}$ & $14.5(0.3)^{a}$ & $14.1(0.3)^{\mathrm{a}}$ \\
\hline Satiation & $\begin{array}{l}\text { Ad libitum } \\
\text { intake }(\mathrm{g})\end{array}$ & $344(15)^{a b}$ & $355(15)^{a}$ & $333(13)^{b}$ & $355(16)^{a}$ & $349(11)^{a}$ & $345(10)^{a}$ & $339(10)^{b}$ & $356(11)^{a}$ \\
\hline
\end{tabular}

269 Within a row and within each category [4 samples (low/high viscosity-small/large particles); average yogurt

270 (high and low viscosity); average granola (small and large)], means containing the same letter are not

271 significantly different $(p<0.05)$.

272

$273 \quad$ 3.2. Liking, familiarity and desire to eat the yogurt again

274 Yogurt viscosity had a significant effect on liking assessed after the first spoon $(p=0.001)$, with

275 a decrease in viscosity decreasing liking by 5\% (Table 2). Decreasing viscosity also decreased

276 familiarity $(p<0.0001)$ and desire to eat the yogurt again $(p=0.001)$. None of the hedonic 
measures were affected by granola particle size. Liking assessed after the last spoon and differences in liking (calculated by subtracting liking scores rated after first and last spoon) did not differ significantly between samples. Interactions yogurt*granola were not significant. Results showed a weak correlation between liking and ad libitum intake $(r=0.20 ; p<0.0001)$.

\subsection{Oral Processing Behaviour}

Eating duration (s), total oral exposure time (s), total inter-spoon interval (s) and chewing rate $\left(\mathrm{min}^{-1}\right)$ did not differ significantly between samples. The total number of chews was significantly affected by granola particle size $(p=0.013)$, with small particles requiring on average 20 more chews than large particles per eating event. A decrease in viscosity increased the total number of spoons and swallows and spooning rate $(p<0.0001)$. Interactions yogurt*granola were not significant.

The number of chews per spoonful decreased with decreasing viscosity by 1.4 chews/spoon $(p<0.0001)$ and increased with decreasing particle size by 0.9 chews/spoon $(p<0.0001)$. Oral exposure time per spoon decreased by $1.2 \mathrm{~s} /$ spoon with decreasing viscosity $(p<0.0001)$. Eating rate $(\mathrm{g} / \mathrm{min})$ was significantly affected by granola particle size $(\mathrm{p}<0.0001)$, with yogurt with smaller granola particles being consumed $5 \mathrm{~g} / \mathrm{min}$ slower than yogurt with large granola particles (relative difference of $7 \%$ ) (Figure $1 \mathrm{~A})$. Eating rate $(\mathrm{g} / \mathrm{min}$ ) was not significantly influenced by yogurt viscosity. Spoon size (i.e. the average amount of yogurt consumed per spoonful) decreased with decreasing viscosity $(p<0.0001)$ and particle size $(p=0.001)$, by 0.9 and 0.8 $\mathrm{g} /$ spoonful respectively. Interactions yogurt*granola were not significant.

\subsection{Ad libitum food intake}

Granola particle size was the only factor that significantly affected ad libitum intake $(p=0.003)$, with a decrease in particle size decreasing intake by $17 \mathrm{~g}$ representing a relative reduction of $5 \%$ (Figure 1B and Table 2). Interactions yogurt*granola were not significant. 

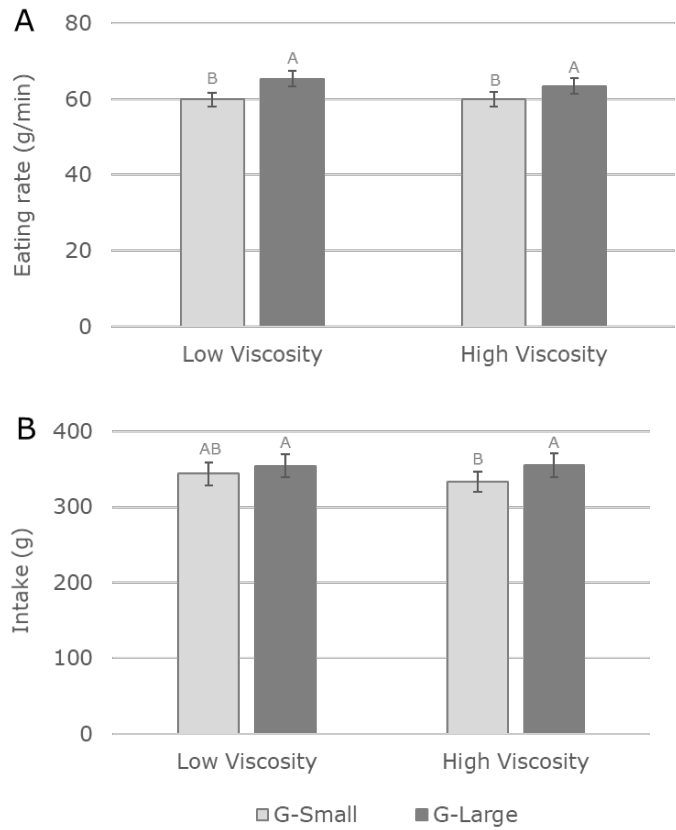

Figure 1. (A) Eating rate and (B) ad libitum intake of yogurts differing in viscosity and granola particle size (mean \pm SEM) $(n=104)$. Different letters indicate significant differences at $\mathrm{p}<0.05$.

Table 3 shows the inter-relationships between ad libitum intake and all oral processing parameters investigated in this study. Eating rate $(r=0.63 ; p<0.0001)$ and spoon size $(r=$ $0.47 ; p<0.0001$ ) were positively correlated with intake, demonstrating that yogurts consumed faster and with larger spoonfuls were consumed in higher amounts. Eating rate had a negative weak correlation with total oral exposure time $(r=-0.17 ; p<0.001)$ and oral exposure time/spoon $(r=-0.27 ; p<0.0001)$, indicating that the longer the food stays in the oral cavity, the slower the rate of consumption. Larger spoon size was strongly associated to faster eating rates $(r=0.62 ; p<0.0001)$. The positive strong correlations between total number of chews and total oral exposure time $(r=0.89 ; p<0.0001)$ and between chews/ spoon and oral exposure time/spoon $(r=0.87 ; p<0.0001)$ confirm that products are kept longer in the mouth when they are chewed for longer. Opposite to what we expected, results showed a strong positive correlation between total number of chews and intake $(r=0.62 ; p<0.0001)$. The higher the total number of chews $(r=0.86 ; p<0.0001)$, spoons $(r=0.67 ; p<0.0001)$ and swallows $(r=0.74 ; p<0.0001)$, the longer the total eating duration. A faster spooning rate was related to smaller spoon size $(r=-0.50 ; p<0.0001)$, lower number of chews/spoon $(r=$ $-0.74 ; p<0.0001)$ and shorter oral exposure time/spoon $(r=-0.86 ; p<0.0001)$. 
Table 3. Pearson correlation coefficients for ad libitum intake and all oral processing 327 parameters.

\begin{tabular}{|c|c|c|c|c|c|c|c|c|c|c|c|c|}
\hline Variables & $\begin{array}{l}\text { Intake } \\
(\mathrm{g})\end{array}$ & $\begin{array}{l}\text { Eating } \\
\text { duration } \\
\text { (s) }\end{array}$ & $\begin{array}{l}\text { Eating } \\
\text { rate } \\
(\mathrm{g} / \mathrm{min})\end{array}$ & $\begin{array}{l}\text { Total } \\
\text { spoons } \\
(n)\end{array}$ & $\begin{array}{l}\text { Total } \\
\text { chews } \\
(\mathrm{n})\end{array}$ & $\begin{array}{c}\text { Total } \\
\text { swallows } \\
(n)\end{array}$ & $\begin{array}{c}\text { Oral } \\
\text { exposure } \\
\text { time (s) }\end{array}$ & $\begin{array}{l}\text { Interval } \\
\text { between } \\
\text { spoons } \\
\text { (s) }\end{array}$ & $\begin{array}{l}\text { Spoon } \\
\text { size }(g)\end{array}$ & $\begin{array}{l}\text { Spooning } \\
\text { rate } \\
\left(\mathrm{min}^{-1}\right)\end{array}$ & $\begin{array}{l}\text { Chewing } \\
\text { rate } \\
\left(\mathrm{min}^{-1}\right)\end{array}$ & $\begin{array}{c}\text { Chews/spoon } \\
\text { (n) }\end{array}$ \\
\hline $\begin{array}{c}\text { Eating duration } \\
(\mathrm{s})\end{array}$ & $\begin{array}{l}0.62 \\
* * * *\end{array}$ & & & & & & & & & & & \\
\hline $\begin{array}{c}\text { Eating rate } \\
(\mathrm{g} / \mathrm{min})\end{array}$ & $\begin{array}{l}0.63 \\
* * * * \\
\end{array}$ & $\begin{array}{c}-0.15 \\
* *\end{array}$ & & & & & & & & & & \\
\hline Total spoons (n) & $\begin{array}{l}0.56 \\
* * * *\end{array}$ & $\begin{array}{l}0.67 \\
* * * *\end{array}$ & 0.06 & & & & & & & & & \\
\hline Total chews (n) & $\begin{array}{l}0.62 \\
* * * *\end{array}$ & $\begin{array}{l}0.86 \\
* * * *\end{array}$ & -0.06 & $\begin{array}{l}0.60 \\
* * * *\end{array}$ & & & & & & & & \\
\hline $\begin{array}{c}\text { Total swallows } \\
\text { (n) }\end{array}$ & $\begin{array}{l}0.64 \\
* * * *\end{array}$ & $\begin{array}{l}0.74 \\
* * * *\end{array}$ & 0.08 & $\begin{array}{l}0.78 \\
* * * *\end{array}$ & $\begin{array}{l}0.67 \\
* * * *\end{array}$ & & & & & & & \\
\hline $\begin{array}{c}\text { Total oral } \\
\text { exposure time } \\
(\mathrm{s})\end{array}$ & $\begin{array}{l}0.61 \\
* * * *\end{array}$ & $\begin{array}{l}0.98 \\
* * * *\end{array}$ & $\begin{array}{l}-0.17 \\
* * *\end{array}$ & $\begin{array}{l}0.66 \\
* * * *\end{array}$ & $\begin{array}{l}0.89 \\
* * * *\end{array}$ & $\begin{array}{l}0.74 \\
* * * *\end{array}$ & & & & & & \\
\hline $\begin{array}{c}\text { Total interval } \\
\text { between spoons } \\
(\mathrm{s})\end{array}$ & $\begin{array}{l}0.35 \\
* * * *\end{array}$ & $\begin{array}{l}0.63 \\
* * * *\end{array}$ & -0.01 & $\begin{array}{l}0.42 \\
* * * *\end{array}$ & $\begin{array}{l}0.37 \\
* * * *\end{array}$ & $\begin{array}{l}0.43 \\
* * * *\end{array}$ & $\begin{array}{l}0.46 \\
* * * *\end{array}$ & & & & & \\
\hline Spoon size $(\mathrm{g})$ & $\begin{array}{l}0.47 \\
* * * *\end{array}$ & -0.02 & $\begin{array}{l}0.62 \\
* * * *\end{array}$ & $\begin{array}{l}-0.38 \\
* * * *\end{array}$ & 0.03 & $\begin{array}{c}-0.10 \\
*\end{array}$ & -0.01 & -0.05 & & & & \\
\hline $\begin{array}{c}\text { Spooning rate } \\
\left(\mathrm{min}^{-1}\right)\end{array}$ & $\begin{array}{c}0.10 \\
*\end{array}$ & $\begin{array}{c}-0.11 \\
* \\
\end{array}$ & $\begin{array}{l}0.23 \\
* * * *\end{array}$ & $\begin{array}{l}0.62 \\
* * * *\end{array}$ & -0.05 & $\begin{array}{l}0.25 \\
* * * * \\
\end{array}$ & $\begin{array}{c}-0.10 \\
* \\
\end{array}$ & -0.08 & $\begin{array}{l}-0.50 \\
* * * *\end{array}$ & & & \\
\hline $\begin{array}{c}\text { Chewing rate } \\
\left(\mathrm{min}^{-1}\right)\end{array}$ & $\begin{array}{c}0.13 \\
* *\end{array}$ & -0.05 & $\begin{array}{l}0.19 \\
* * * *\end{array}$ & 0.02 & $\begin{array}{l}0.41 \\
* * * * \\
\end{array}$ & 0.02 & -0.02 & $\begin{array}{c}-0.14 \\
* *\end{array}$ & 0.07 & $\begin{array}{c}0.12 \\
*\end{array}$ & & \\
\hline Chews/spoon (n) & -0.03 & $\begin{array}{c}0.11 \\
*\end{array}$ & $\begin{array}{l}-0.18 \\
* * * *\end{array}$ & $\begin{array}{l}-0.47 \\
* * * *\end{array}$ & $\begin{array}{l}0.32 \\
* * * *\end{array}$ & $\begin{array}{l}-0.16 \\
* * *\end{array}$ & $\begin{array}{l}0.16 \\
* * *\end{array}$ & $\begin{array}{c}-0.11 \\
*\end{array}$ & $\begin{array}{l}0.50 \\
* * * *\end{array}$ & $\begin{array}{l}-0.74 \\
* * * *\end{array}$ & $\begin{array}{l}0.39 \\
* * * *\end{array}$ & \\
\hline $\begin{array}{c}\text { Oral exposure } \\
\text { time/spoon (s) }\end{array}$ & -0.08 & $\begin{array}{c}0.15 \\
* *\end{array}$ & $\begin{array}{l}-0.27 \\
* * * *\end{array}$ & $\begin{array}{l}-0.53 \\
* * * *\end{array}$ & $\begin{array}{c}0.14 \\
* *\end{array}$ & $\begin{array}{l}-0.20 \\
* * * *\end{array}$ & $\begin{array}{l}0.18 \\
* * * *\end{array}$ & -0.05 & $\begin{array}{l}0.54 \\
* * * *\end{array}$ & $\begin{array}{l}-0.86 \\
* * * *\end{array}$ & -0.06 & $\begin{array}{l}0.87 \\
* * * *\end{array}$ \\
\hline
\end{tabular}

\subsection{Texture, oral processing behaviour and food intake}

332 In this study we investigated the effect of small texture modifications on food intake. Yogurt viscosity was varied approximately by a factor of $1.7 x$ while granola particle size was varied by a factor of $2 x$. We quantified instrumentally the differences in viscosity and particle size, but we did not quantify how changes in these product properties influenced sensory perception of the yogurts with granola particles.

337 Results indicate that a decrease in granola particle size from $12 \mathrm{~mm}$ to $6 \mathrm{~mm}$ yielded a $7 \%$ $338(5 \mathrm{~g} / \mathrm{min})$ reduction in eating rate and a $5 \%(17 \mathrm{~g})$ reduction in food intake. Changes in oral processing behaviour can explain this effect of particle size on eating rate and ad libitum intake. Yogurts with $6 \mathrm{~mm}$ granola particles required on average 20 more chews per eating event and 0.9 more chews per spoonful in comparison to yogurts with $12 \mathrm{~mm}$ granola particles. This is in agreement with previous studies that reported an increase in chewing activity being accompanied by a decrease in eating rate and consequently in intake (Smit et al. 2011; Bolhuis et al 2014; Forde et al., 2013; Lasschuijt et al., 2017; McCrickerd et al 2017). Increasing chewing activity has also been shown to impact satiety and the profile of gut hormones related to appetite (Li et al., 2011; Zhu et al., 2013a). As the number of mastication cycles of a test meal increased from 15 to 40, Li et al. (2011) observed a decrease in postprandial ghrelin concentration and an increase in postprandial glucagon-like peptide 1 and cholecystokinin 350 concentrations in subjects with both normal-weight and obesity. Similarly, increasing the chewing of pizza from 15 to 40 chews increased the plasma levels of glucose, insulin, glucose- 
dependent insulinotropic peptide (GIP) and cholecystokinin and tended to decrease ghrelin concentration (Zhu et al., 2013a).

We observed an increase in chewing activity with reduction in granola particle size (Table 2) which might seem counter-intuitive on a first glance. Similar results were observed by Eck et al., (submitted) in a study that compared the eating behaviour of carrots cut in different sizes and shapes. Total mastication time and number of chews were higher and eating rate was lower for carrots cut into elongated julienne pieces in comparison to carrots cut into cubes. These results can be explained by considering the volume of particles and its effect on oral processing behaviour. In our study, the weight percentage of granola particles added to yogurts was the same for all samples $(15 \% \mathrm{w} / \mathrm{w})$. Hence, the number of granola particles and the corresponding total volume of particles differed between yogurts with small and large granola particles. The number and volume of small $(6 \mathrm{~mm})$ granola particles was higher than that of large $(12 \mathrm{~mm})$ particles. Kohyama et al. (2007) observed that a higher number of chews and longer mastication time were required for the oral processing of finely cut raw carrots and cucumbers in comparison to the same weight of vegetables presented as a single cube. However, when the authors compared the oral processing behaviour of the vegetables with same volume, finely cut carrots and cucumbers were chewed less and for a shorter time than the vegetable cubes of the same volume. The authors concluded that the increase in volume of finely cut foods was the reason for the increase in mastication efforts (Kohyama et al., 2007). These findings are further supported by Imai et al. (1995), who reported that the concentration of particles had a stronger effect on texture perception than the size of particles, with a higher concentration of particles (larger volume) resulting in stronger grittiness sensations. We suggest that the volume of granola particles added to yogurts and not the size of particles per se was the driver of oral processing behaviour, as the larger number of small granola particles required more chews per spoon than a smaller number of large particles. Our results suggest that modifications in the size of solid particles added to foods aiming at increasing the number of chews per spoon can be a strategy to modulate oral exposure time and eating rate and consequently regulate food intake. The intake regulation accomplished through this strategy might probably be maintained overtime after repeated exposure as the texture properties of the foods are only slightly modified, preserving the product identity to a large extent. Further research is needed comparing different foods to which solid particles have been added to investigate whether the observed effects of particle size and texture modification on ad libitum food intake are generalizable and can be sustained after repeated exposure.

Additionally, decreasing granola particle size by a factor of $2 x$ decreased spoon size. The effect of bite size on the regulation of food intake has been described previously, with smaller bites/sips being associated to decreases in food intake (Weijzen et al., 2009; Zijlstra et al., 2009; Bolhuis et al., 2013). In our study, spoon size and intake were positively correlated $(r=0.473, p<0.0001)$ (Table 3), suggesting that the larger the amount of yogurt per spoonful, the higher the amount of food consumed. Therefore, the decrease in spoon size might also explain the decrease in intake observed for yogurt samples with small granola particles.

Eating rate and food intake within a meal were not affected by small variations in the viscosity of yogurts. The viscosity differences between low and high viscosity yogurts ranged from $1.57 \mathrm{x}$ to $1.81 \mathrm{x}$. We suggest that the explanation for this result is the change in spoon size (amount of yogurt consumed per spoonful) according to viscosity. We observed that the high viscosity yogurt was consumed with larger spoon sizes $(0.9 \mathrm{~g} / \mathrm{spoonful})$, as a larger amount of thick yogurt can be hold on a spoon in comparison to thin yogurt. As mentioned previously, increases 
in spoon/bite size have been related to increases in intake (Weijzen et al., 2009; Zijlstra et al., 2009; Bolhuis et al., 2013). Therefore, even though for the high viscosity yogurt the number of chews/spoon was higher and oral exposure time/spoon was longer compared to the thin yogurt, a concomitant increase in spoon size might have overruled the expected effect of viscosity on intake. Additionally, the variation in yogurt viscosity in this study might not have been large enough to strongly affect eating rate and ad libitum intake.

The $7 \%$ reduction in eating rate $(5 \mathrm{~g} / \mathrm{min})$ and $5 \%$ reduction in food intake $(17 \mathrm{~g})$ resulted from decreasing granola particle size by a factor of $2 x$ were smaller than those observed in other studies for foods differing considerably in texture (Zijlstra et al., 2009; Lasschuijt et al., 2017). However, small but consistent differences in eating rate and intake can account for large differences in the cumulative energy intake across eating occasions. In an inpatient feeding trial that compared unprocessed and ultra-processed diets, Hall et al. (2019) have shown that an average difference of just $17 \mathrm{kcal} / \mathrm{min}$ or $7.4 \pm 0.9 \mathrm{~g} / \mathrm{min}$ was sufficient to support a cumulative increase in energy intake of $508 \mathrm{kcal} / \mathrm{day}$.

Even though it is well accepted that one should slow down the eating rate to prevent overconsumption, it remains a challenge to change eating rate of individuals over the long term. McCrickerd \& Forde (2017) reported that individuals were consistent in their eating rates in the consumption of four different meals, with the eating rate of one occasion being able to predict the eating rate and energy intake of subsequent meals. This suggests that eating rate is an individual's characteristic. In a study that included 272 subjects, Henry et al., (2018) observed a relationship between basal metabolic rate and eating rate. If consumers adapt their eating rates to their energy requirements, in other words, if eating rate is regulated by a physiological need, individuals will respond differently to the strategies that aim to regulate food intake. In our study we did not observe a significant relationship between BMI and eating rate or food intake. This is probably due to the fact that the participants of our study did not differ greatly with respect to BMI (BMI: $21 \pm 2 \mathrm{~kg} / \mathrm{m}^{2}$ ranging from 18 to $26 \mathrm{~kg} / \mathrm{m}^{2}$ ). Comparing groups of subjects with normal-weight and overweight/obesity, Shah et al. (2014) observed that decreasing eating rate was efficient to decrease energy intake only for the first group. Women that presented either decelerated or linear eating patterns responded differently when forced to increase and decreased their eating rates (Zandian et al., 2009). Reducing eating decreased intake for the linear eaters, but did not affect intake among the decelerated eaters. Martin et al. (2007) reported that slower eating rate reduced intake only for male subjects. Further studies are therefore required to quantify the extent to which small modifications in texture can consistently reduce eating rate and food intake across different consumer groups.

\subsection{Limitations}

Even though consumers were not aware of the main aims of the study and everything was arranged in a way they could behave naturally, it is worth emphasizing that the results of this study are based on an ad libitum consumption study performed in a laboratory setting. Further studies are required to investigate whether the observed impact of food texture on eating rate and intake can be extrapolated to real life eating occasions after multiple exposures. 
As explained earlier, two samples containing powder-like granola were excluded from the data analysis since this type of granola displayed a very different behaviour upon mixing with yogurt in comparison to small and large granola particles. Including other sets of granola particles, varying other texture properties such as the hardness/brittleness of granola particles or using other types of particles such as fruits pieces and nuts would allow generalizing the findings on the effect of small modifications of texture on eating rate and food intake. While yogurts with added granola pieces or fruit pieces are commonly consumed as a breakfast meal in The Netherlands and some other European countries, these products are not consumed as a meal or breakfast in many other countries and cultures. We suggest that future studies should consider modifying the texture of different foods including complex, mixed meals since those are the main contributors to energy intake and might allow to generalize findings across foods, meal occasions, eating cultures and countries.

Even though we aimed at having a similar palatability, a decrease in yogurt viscosity had a significant effect on liking and familiarity with the low viscosity yogurt being slightly less liked and having lower familiarity than the high viscosity yogurt (table 2 ). This drawback should be avoided in studies quantifying ad libitum food intake.

Lastly, the population in this study consisted of young, healthy participants ( $21 \pm 3 \mathrm{y}$, range: 18 $36)$ with similar BMI values $\left(21 \pm 2 \mathrm{~kg} / \mathrm{m}^{2}\right.$, range: $\left.18-26\right)$. To quantify whether small texture modifications can consistently modify intake independently of the energy requirement of subjects, specific target groups such as fast eaters, the elderly and subjects with overweight should be investigated. We speculate that the relative impact of a food texture modification on eating rate and ad libitum food intake depends on the eating style of the consumer.

\section{CONCLUSIONS}

Small texture variations were sufficient to change oral processing behaviour and ad libitum intake. Decreasing the size of granola particles from $12 \mathrm{~mm}$ to $6 \mathrm{~mm}$ significantly decreased ad libitum intake by $17 \mathrm{~g}$ (relative reduction of $5 \%$ ). This reduction in intake was related to an increase in the number of chews per spoon and to a decrease in eating rate and spoon size. We suggest that the volume of granola particles added to the yogurt and not the size of particles per se was the driver of oral processing behaviour, as the larger number of small granola particles required more chews per spoon than a smaller number of large particles. The variation in viscosity of yogurts (1.57x to $1.81 \mathrm{x}$ difference) did not affect eating rate and ad libitum food intake. We suggest that the concomitant increase in spoon size, number of chews per spoon and oral exposure time per spoon for the high viscosity yogurt might explain the lack of effect of viscosity on ad libitum intake. Liking and familiarity were negatively affected by a decrease in viscosity. This shows that special attention should be given by food manufacturers when modulating the texture properties of foods as not all modifications will result in desirable effects on food intake and consumer acceptability. 
Our results show the potential of controlling intake by slight variations in food texture. Further studies are required to investigate whether in a real-life setting, reductions in intake can be sustained after multiple exposures to the same product across different consumer groups.

\section{ACKNOWLEDGEMENTS}

The research was funded by the European Sensory Network (ESN), an international network of research institutions and industrial partners in sensory and consumer sciences. ESN and Wageningen University are jointly responsible for the study design, data collection and analysis, decision to publish, and preparation of the manuscript. The authors have declared that no conflicting interests exist.

The authors appreciated the support and guidance of the ESN Steering Committee throughout the project: Stine Møller (DuPont), Riette de Kock (University of Pretoria), Martijn Veltkamp (FrieslandCampina) and Saara Pentikäinen (VTT). The authors thank FrieslandCampina for kindly providing the yogurt products, BioFamilia for providing the granola products and Dr. Dieuwerke Bolhuis for her valuable comments on the manuscript.

\section{REFERENCES}

Aguayo-Mendoza, M. G., Ketel, E. C., van der Linden, E., Forde, C. G., Piqueras-Fiszman, B., \& Stieger, M. (2019). Oral processing behaviour of drinkable, spoonable and chewable foods is primarily determined by rheological and mechanical food properties. Food Quality Preference, 71,87-95. https://doi.org/10.1016/j.foodqual.2018.06.006.

Bolhuis, D. P., Forde, C. G., Cheng, Y., Xu, H., Martin, N., \& de Graaf, C. (2014). Slow food: Sustained impact of harder foods on the reduction in energy intake over the course of the day. PLoS One, 9(4), e93370. https://doi: 10.1371/journal.pone.0093370.

Bolhuis, D. P., Lakemond, C. M., de Wijk, R. A., Luning, P. A., \& de Graaf C. (2013). Consumption with large sip sizes increases food intake and leads to underestimation of the amount consumed. PLoS One, 8(1), e53288. https://doi.org/10.1371/journal.pone.0053288.

de Graaf, C. (2012). Texture and satiation: the role of oro-sensory exposure time. Physiology \& Behavior, 107(4), 496-501. https://doi.org/10.1016/j.physbeh.2012.05.008.

de Wijk, R. A., Zijlstra, N., Mars, M., de Graaf, C. \& Prinz, J. F. (2008). The effects of food viscosity on bite size, bite effort and food intake. Physiology \& Behavior, 95(3), 527-532. https://doi.org/10.1016/j.physbeh.2008.07.026.

Ferriday, D., Bosworth, M., Godinot, N., Martin, N., Forde, C. G., van Den Heuvel, E., Appleton, S., Mercer Moss, F., Rogers, P. J., \& Brunstrom, J. M. (2016). Variation in the oral processing of everyday meals is associated with fullness and meal size; a potential nudge to reduce energy intake? Nutrients, 8(5), e315. https://doi: 10.3390/nu8050315. 
512 Forde, C. G., Lim, C. H. M., Leong, C., Chia, E. M. E., \& McCrickerd, K. (2017). Fast or slow513 foods? Describing natural variations in oral processing characteristics across a wide range of 514 Asian foods. Food \& Function, 8 (2), 595-606. https://doi: 10.1039/c6fo01286h.

515 Forde, C. G., van Kuijk, N., Thaler, T., de Graaf, C., \& Martin, N. (2013). Oral processing 516 characteristics of solid savoury meal components, and relationship with food composition, 517 sensory attributes and expected satiation. Appetite, 60(1), 208-219. https://doi: $518 \quad 10.1016 / j$.appet.2012.09.015.

519 Hall, K. D., Ayuketah, A., Brychta, R., Cai, H., Cassimatis, T., Chen, K. Y., . . Darcey, V. (2019). Ultra-Processed Diets Cause Excess Calorie Intake and Weight Gain: An Inpatient Randomized Controlled Trial of Ad Libitum Food Intake. Cell Metabolism. https://doi.org/10.1016/j.cmet.2019.05.008.

Hennequin M., Allison, P.J., Veyrunea, J.L., Fayec, M., \& Peyron, M. (2005). Clinical evaluation of mastication: validation of video versus electromyography. Clinical Nutrition, 24(2):314-320. https://doi.org/10.1016/j.clnu.2004.11.010.

Henry, C. J., Ponnalagu, S., Bi, X., \& Forde, C. (2018). Does basal metabolic rate drive eating rate? Physiology \& Behavior, 189, 74-77. https://doi.org/10.1016/j.physbeh.2018.03.013.

528 Imai, E., Hatae, K., \& Shimada, A. Oral perception of grittiness (1995). Journal of Texture Studies, 26(5):561-76. https://doi.org/10.1111/j.1745-4603.1995.tb00804.x.

530 Kohyama, K., Nakayama, Y., Yamaguchi, I., Yamaguchi, M., Hayakawa F., \& Sasaki, T. (2007) 531 Mastication efforts on block and finely cut foods studied by electromyography. Food Quality and 532 Preference, 18(2): 313-320. https://doi.org/10.1016/j.foodqual.2006.02.006.

533 Lasschuijt, M. P., Mars, M., Stieger, M., Miquel-Kergoat, S., de Graaf, C., \& Smeets, P. A. M. (2017). Comparison of oro-sensory exposure duration and intensity manipulations on satiation. Physiology \& Behavior, 176, 76-83. https://doi.org/10.1016/j.physbeh.2017.02.003.

540 Martin, C. K., Anton, S. D., Walden, H., Arnett, C., Greenway, F. L., \& Williamson, D. A. (2007). 541 Slower eating rate reduces the food intake of men, but not women: Implications for behavioral 542 weight control. Behaviour Research and Therapy, 45(10), 2349-2359. 543 https://doi.org/10.1016/j.brat.2007.03.016.

544 McCrickerd, K., \& Forde., C. G. (2017). Consistency of eating rate, oral processing behaviours 545 and energy intake across meals. Nutrients. 9(8), e891. https://doi: 10.3390/nu9080891.

546 McCrickerd, K., Lim, C. M. H., Leong, C., Chia, E. M., \& Forde, C. G. (2017). Texture-based 547 differences in eating rate reduce the impact of increased energy density and large portions on 548 meal size in adults. The Journal of Nutrition, 147(6), 1208-1217. https://doi: $54910.3945 /$ jn.116.244251. 
Robinson, E., Almiron-Roig, E., Rutters, F., de Graaf, C., Forde, C. G., Tudur Smith, C., Nolan, S. J., Jebb, \& S. A. (2014). A systematic review and meta-analysis examining the effect of eating rate on energy intake and hunger. American Journal of Clinical Nutrition, 100(1), 123-51. https://doi: 10.3945/ajcn.113.081745.

Shah, M., Copeland, J., Dart, L., Adams-Huet, B., James, A., \& Rhea, D. (2014). Slower eating speed lowers energy intake in normal - weight but not overweight/obese subjects. Journal of the Academy of Nutrition and Dietetics, 14(3), 393-402. https://doi.org/10.1016/j.jand.2013.11.002.

Smit, H. J., Kemsley, E. K., Tapp, H. S., \& Henry, C. J. (2011). Does prolonged chewing reduce food intake? Fletcherism revisited. Appetite, 57(1), 295-298. https://doi.org/10.1016/j.appet.2011.02.003.

Tarrega, A., Marcano, J., \& Fiszman, S. (2016). Yoghurt viscosity and fruit particles affect satiating capacity expectations. Food Research International, 89, 574-581. https://doi.org/10.1016/j.foodres.2016.09.011.

Wee, M. S. M., Goh, A. T., Stieger, M., \& Forde, C. G. (2018). Correlation of instrumental texture properties from textural profile analysis (TPA) with eating behaviours and macronutrient composition for a wide range of solid foods. Food \& Function, 9(10), 5301-5312. https://doi: $10.1039 /$ c8fo00791h.

Weijzen PLG, Smeets PAM, de Graaf C (2009) Sip size of orangeade: Effects on intake and sensory-specific satiation. British Journal of Nutrition, 102(7): 1091-1097. https://doi.org/10.1017/S000711450932574X.

Zandian, M., Ioakimidis, I., Bergh, C., Brodin, U., \& Södersten, P. (2009). Decelerated and linear eaters: effect of eating rate on food intake and satiety. Physiology \& Behavior, 96(2), 270-275. https://doi: 10.1016/j.physbeh.2008.10.011.

Zhu, Y., Hsu, W. H., \& Hollis, J. H. (2013a). Increasing the number of masticatory cycles is associated with reduced appetite and altered postprandial plasma concentrations of gut hormones, insulin and glucose. British Journal of Nutrition, 110(2), 384-390. https://doi.org/10.1017/S0007114512005053.

Zhu, Y., Hsu, W. H., \& Hollis, J. H. (2013b). The impact of food viscosity on eating rate, subjective appetite, glycemic response and gastric emptying rate. PLoS ONE, 8(6), e67482. https://doi.org/10.1371/journal.pone.0067482.

Zijlstra, N., de Wijk, R., Mars, M., Stafleu, A., \& de Graaf, C. (2009). Effect of bite size and oral processing time of a semisolid food on satiation. The American Journal of Clinical Nutrition, 90(2), 269-275. https://doi.org/10.3945/ajcn.2009.27694.

Zijlstra, N., Mars, M., de Wijk, R.A., Westerterp-Plantenga, M.S., \& de Graaf, C. (2008). The effect of viscosity on ad libitum food intake. International. Journal of Obesity, 32(4), 676-683. https://doi: 10.1038/sj.ijo.0803776.

van Eck, A., Wijne C., Fogliano, V., Stieger, M., \& Scholten, E. Shape up! How shape, size and addition of condiments influence eating behavior of vegetables. (submitted). 